\title{
THE PROSPECTS FACING AN INDEPENDENT SCOTLAND IN THE EURO-ZONE ALONGSIDE THE REST OF THE UK
}

\author{
Sheila Dow* \\ Published in Scottish Affairs 45 (Autumn) 2003, 60-71.
}

\section{INTRODUCTION}

This paper explores the scenario of Scotland belonging to EMU as an independent country, with the rest of the UK also a member. We consider transitional issues, (the order in which various events occur turns out to be potentially crucial), the implications of Maastricht, the likely effects on the Scottish economy of being in EMU, and finally the policy options open to an independent Scottish government.

\section{TRANSITION ROUTE TO SCENARIO}

Scotland's conditions of entry could be quite different, depending on whether Scotland joined first as an independent nation, or became independent having already belonged to EMU as part of the UK.

If Scotland became independent after the UK had joined EMU then Scotland's entry could be relatively straightforward. It would be unlikely that Scotland would, in effect, be expelled, as long as the new Scottish government undertook to continue to abide by the principles of EMU. There is a contrary argument: namely, that the EU might resist Scottish entry to EMU on the grounds that this could set a potentially destabilising precedent, encouraging some other European regions to seek independence and automatic EMU membership. But the special political importance of UK entry into EMU could well tip the balance in favour of easing entry for an independent Scotland. If the UK were already in EMU, it would be inconceivable that Scotland would adopt an interim new currency in order to re-enter at a different exchange rate. Thus options would effectively have been closed off for Scotland by already having adopted the euro, as a result of the UK having entered EMU.

Under the converse scenario, of Scottish independence before UK entry into EMU, the Scottish government would be faced with important policy questions. In particular, the issue would need to be addressed as to whether to issue a separate Scottish currency before entering EMU. Possible advantages of doing this include:

- the symbolic importance for a nation state of having its own currency

- the possibility it might provide of independence from RUK monetary policy

- the possibility of entering EMU at a lower, more competitive, exchange rate than pound sterling

- as a source of seignorage revenue ${ }^{1}$

- as a route through which Scotland might eventually be part of the European System of Central Banks (ESCB) and

\footnotetext{
* Sheila Dow is Professor of Economics at the University of Stirling with regional finance one of her interests.

${ }^{1}$ Seignorage is the income received by the issuer of a currency, as the difference between its market value and its cost of production.
} 
- as a source of better accounting of trade and capital flows.

There could be advantages in seizing the moment of independence as the best time to make a change of currency; such timing might help to counteract some of the political and psychological difficulties with introducing a new currency.

There could be significant difficulties in persuading Scots to switch away from pounds sterling as the conventional means of payment, if that was expected to be the RUK currency for a long time to come. The level of trade and factor movements between Scotland and RUK would remain high after independence. Currencies cannot be imposed on a market which displays a preference for another currency. The risk would thus be significant of demonetisation (the refusal to accept a particular form of money). This risk would be higher if the exchange rate with the pound sterling were variable.

Nevertheless, there are examples of small countries which successfully introduced and maintained separate currencies without demonetisation. Although trade with RUK may tend to be denominated in pounds sterling, this would be offset by public sector transactions in Scotland (including tax payments) being denominated in the Scottish currency. Further, the Scottish Parliament could declare the Scottish currency to be legal tender, which would reinforce usage. ${ }^{2}$

Still, the possibility of demonetisation remains an issue to be faced. The launch of a Scots currency could only be reasonably sure of avoiding demonetisation if it were pegged one-for-one with pounds sterling. While such a peg would limit the scope for any independence in terms of exchange rate policy or monetary policy, the other benefits noted above could be sufficient to warrant such a move.

The alternative to a one-for-one peg need not be floating. There is the possibility of pegging at a different rate, chosen to suit Scotland's relative competitiveness. This option would still not allow much scope for an independent monetary policy in the run-up to joining EMU, but it would have two distinct advantages. First, in the run-up to EMU, it is difficult to support an exchange rate which does not reflect relative competitiveness; if the one-for-one rate were too high, Scotland would require access to sufficient borrowed reserves to maintain payments balance. Second, it would pave the way for entry into EMU at a rate appropriate for the Scottish economy rather than the UK economy. While a floating rate might be seen as a better way of establishing what that rate should be, exchange rate determination, especially in the short-run, does not necessarily reflect relative competitiveness.

If Scottish entry into EMU were to be long delayed, for whatever reason, then the pressure for considering moving away from parity with the pound sterling would increase. Indeed the longer Scotland delayed, the more it would have to justify eligibility in its own right anyway, so that entry at a suitable exchange rate with the euro, independent of pound sterling, would be warranted.

Regardless of whether Scotland joined EMU before or after RUK, an independent Scotland would require the institutional structure of an independent nation. This institutional structure would include an independent central bank and a separate bank supervisory agency. If Scotland were to become independent and seek EMU entry, its central bank governor could belong to the General Council of the European System of Central Banks until joining EMU, when membership of Governing Council would be available. The greater the involvement of Scotland's central bank governor, the

\footnotetext{
${ }^{2}$ This does not guarantee general usage.
} 
greater the scope for input into European monetary policy-making. But ultimately, Scotland would be tied to the single European monetary policy once she moved to full EMU membership.

Membership of EMU would constrain the powers of a Scottish central bank in further respects. EMU would preclude the Scottish government from borrowing from its central bank or having the central bank manage its debt. Further, the central bank and supervisory agency would need to address the European policy of harmonisation of functions (eg deposit insurance) in Europe. Considerable harmonisation has already been achieved, but there continues to be significant differentiation of treatment across Europe, in terms of accounting, taxation, regulation and conventional practice.

\section{POSITION VIS-À-VIS MAASTRICHT CRITERIA}

If the UK had already joined EMU before Scotland became independent, the Maastricht criteria might be presumed to have been satisfied for Scotland having been part of UK. This is more likely to be the case, the sooner after independence Scotland sought entry. The longer the delay, the more Scottish entry would be seen as separate from UK entry. Once Scotland was in EMU, in any case, the Maastricht Treaty requires that evidence be sought that Scotland was continuing to meet the criteria: this involves the collection of data such as budgetary deficit, debt to GDP ratio, a general price index and the identification of an appropriate long term interest rate. At least, following the 2003 Budget Address, there is the prospect of a Scottish consumer price series.

There is therefore a danger that Scotland might not meet the stability criteria due to measurement or transitional problems. Further the budgetary criterion might not be met if there were a transitional deficit, resulting from the cessation of transfer payments from Westminster. This outcome is not certain, however, not least because there would also need to be a significant one off transfer to Scotland on independence to compensate for loss of joint ownership of a range of UK assets, such as Bank of England gold reserves. But considerable uncertainty would be bound to persist for some time over an independent Scotland's budgetary position.

However, as long as Scotland moved quickly to join EMU it is likely that Scotland would be given some latitude to overcome transitional problems in demonstrating that the Maastricht conditions were continuing to be met, particularly since any instability is unlikely to be dramatic compared to other countries in Europe.

The situation could be similar for Scotland joining EMU ahead of RUK, as long as the UK as a whole had been seen to have met the criteria. It is possible that Scotland would have to prove herself fit for entry on the basis of purely Scottish conditions. That could pose a major problem: the Maastricht criteria data would have to be collected for Scotland, and also satisfy the criteria, over an extended period. But the formal requirements for Scotland might be relaxed because of the political significance of a Scottish application for entry if there were still doubts about the commitment of RUK to eventual entry.

A separate Scottish currency on independence would provide the machinery for later substituting the euro for that currency. Otherwise it would be extraordinarily difficult to manage the introduction of the euro in Scotland ahead of RUK. It would also allow the possibility of letting the Scottish currency depreciate to a value more suitable for the Scottish economy. But it would have to be recognised that anything other than a pegged rate could lengthen the process of assessing eligibility, since a separate, 
floating, currency would invite the need for evidence of currency stability. The alternative option of a rate pegged to pounds sterling which embodied an appropriate depreciation would prevent any instability: but the judgement as to the appropriate degree of depreciation clearly would be crucial.

Individual countries do not of course have an independent choice as to the exchange rate at which they enter EMU. Negotiation is possible, but the existing members would determine the rate of entry, whether it was with respect to the pound or a Scots currency. In fact the political process would be easier with a Scottish pound. Establishing an entry rate for a currency pegged one-to-one with sterling would be highly politically-charged, and would have major effects on foreign exchange markets, given that this would be read as the rate to be set for later RUK entry. The political pressure would be enormous to co-ordinate entry. For Scotland to exercise independence with respect to EMU entry, therefore, as long as RUK delayed entry beyond Scottish independence, the case is strengthened for a separate currency not pegged one-to-one with pounds sterling.

\section{LIKELY EFFECTS ON THE SCOTTISH ECONOMY}

After EMU entry, the Scottish economy would be subject to a number of major external influences. First of all, increased competition in the single European market is likely to lead to a continued process of industrial concentration. There is nothing in the logic of the single European market to ensure that the concentrated industry is evenly distributed between member countries. The overall effect on Scotland is unclear, but to the extent that Scotland benefited from industrial concentration, we could expect to benefit from productivity gains.

Our competitive position would also be affected by the parity at which we entered EMU. If Scotland joined at the same parity as RUK (whether or not by the route of a separate currency pegged to sterling), then Scotland's current position in Europe would be maintained, with an unduly high exchange rate counteracting the scope for productivity gains. However, if Scotland were able to join at a lower parity, the positive dynamic effects could be substantial. As regards general trade patterns, much would depend on relative exchange rates, within the UK, within Europe and also with the rest of the world. Scotland could be disadvantaged by being tied to a weak euro, but at an over-valued exchange rate on entry. This reinforces the importance of considering entry at a lower parity, as well as the wider question of the future prospects of the euro in the world monetary system. Overall, assuming Scotland entered at a competitive rate, it is likely that EMU entry would increase Scotland's intra EU trade.

Another important factor is inward investment: membership of EMU would be expected to increase inward investment in Scotland from Europe, but the relative exchange rate would have a significant bearing on this. In particular, the dollar-euro exchange rate could be significant. A weak euro could encourage inward investment within the euro-zone, attracted by lower costs. Scotland could benefit particularly, with its strong trading links with North America.

Of particular importance to the Scottish economy is the likely impact on the financial sector. The financial sector in Scotland has already been influenced by broader trends in global finance. The entire European financial sector has been going through a process of restructuring into larger units, with the predominant trend being concentration primarily within national boundaries. 
For Scotland, this process is likely to be complete before independence could reasonably be seen to be on the agenda. The sector should be well-placed to compete in RUK and more effectively in the rest of Europe on the basis of a single currency. The transition mechanism to EMU is, however, likely to be of crucial importance. If the Scots currency were to float, this would cause difficulties not only in terms of different denominations of currencies for financial assets and liabilities where currently there is the one denomination of pound sterling, but there would also be the problem of changing valuation along with changing exchange values, and the need to hedge against foreign exchange risk. Financial institutions would probably respond by continuing to denominate in pounds sterling, which poses a threat of demonetisation in Scotland. If there were a fixed parity, however, the required change to procedure would be minimal. Given that financial institutions routinely denominate in a range of currencies, this is unlikely to be an impediment to the strength of the sector in Scotland.

After EMU entry, the Scottish market would itself be more open to outside competition within EMU. Other things being equal, there is always a strong pull towards financial centres; the Scottish financial sector is relatively strong in Europe, so that it has resisted this pull (in Scotland's case, to London) so far. It would be of tremendous importance for an independent Scotland to ensure the continuing strength of the Scottish financial sector: not only with regard to the sector's contribution to output and employment, but also as regards the macroeconomic importance of the credit creation and distribution behaviour of the banking system.

\section{POLICY LEVERS}

Membership of EMU would seriously constrain the policy levers open even to an independent Scotland. The Maastricht Treaty means the removal of exchange rate policy and monetary policy, as well as significant constraints on the scale of fiscal policy. Harmonisation of taxation, regulation and social legislation in Europe put limits on the scope for supply-side policies. Nevertheless, harmonisation does not mean uniformity, so some policy levers would be available. In particular, the composition of taxes and expenditure can be tools of demand management, even when the aggregates are constrained by European limits. Scotland could, for example, reduce some rates of corporate or income tax relative to RUK as a deliberate attempt to influence choices between RUK and Scotland.

Further, a Scottish government could promote the knowledge economy in ways not constrained by harmonisation. First there is scope for a distinctive education policy, building on a distinctive historical tradition. Second there is the scope, within a small, reasonably cohesive, economy to promote synergies between sectors and firms by setting up mechanisms to improve knowledge flows between firms, financial sector and government.

As a nation state member of EMU, Scotland would have a greater say in the design of European macroeconomic policy than at present, although with Enlargement of the EU, Scotland's representation on the Commission would be proportionately small. However it is likely that the European Central Bank (although not its Executive) would continue to have representation from all member central banks, so that Scotland would have significant representation as far as monetary policy was concerned. 
As regards the Maastricht criteria, it may be that more lengthy experience of applying the criteria might lead to their amendment. Indeed there are already indications that the criteria will be modified in the sense that they will be applied to the structural, rather than actual, deficits. There would also still be scope for targeting taxes and benefits, and expenditures, in such a way as to promote an increase in local demand alongside supply side measures. For example, measures to support entrepreneurial activity in declining areas through training, seed capital etc could be underpinned by measures to enhance demand in the local economy. This could be achieved by careful locational direction of government expenditure with an eye on local income multipliers.

Similarly, two major central banking functions are still provided at the national level: these are the lender-of-last-resort facility, and bank supervision (although the ECB's role is evolving, with more interest now in supervisory issues, for example). The EU's 'home country' principle puts the onus for supervision on the central bank of the bank's 'home' country, so that the potential purview of a Scottish central bank might be quite limited. Nevertheless there is scope for a Scottish central bank to enhance the climate of quality in Scottish banking, encouraging further strengthening of the sector within a Europe-wide market.

As EMU precludes central banks from lending to government, the Scottish Treasury could develop a relationship with the Scottish banks as bankers to the government. Because of the central role played by the retail banks in the economic development process, there is clearly scope for constructive dialogue with government over development strategy, where government can contribute the macro perspective to the banks' more micro perspective. If the government were to be providing the banks with the substantial business entailed in handling government accounts, the strength of the mutual relationship would be enhanced.

\section{CAPABILITY OF ADJUSTMENT TO EXTERNAL SHOCKS}

As a member of EMU, Scotland would be vulnerable to shocks arising within EMU. To the extent that the business cycle is successfully harmonised within Europe, demand shocks would be lessened. However, there are concerns as to how successful this harmonisation will be, given that a single European monetary policy may have quite different effects on different types of economy, since the economic response to changing interest rates is not uniform throughout Europe.

If intra-EMU trade increases, then the scope for shocks from outside EMU would be lessened. However, external shocks would not be eliminated, and could be more significant for Scotland than for other members, if we continued our traditional role of specialising in entrepôt trade.

Overall the scope for sector-specific shocks might be increased by the avowed policy of concentrating European economic activity in order to reap economies of scale and scope. Each member state, but more particularly small member states, will become increasingly dependent on fewer industries, and thus more vulnerable to both supply and demand shocks. An appropriate strategy for such economies to reduce vulnerability would be to diversify in a range of niche markets and specialisms.

Within the UK, mechanisms exist for Scotland to be cushioned by fiscal transfers to address particular regional problems. Such transfers are a well-recognised substitute for the exchange rate tool employed within national boundaries. At the European level, the scale of funds dispersed to the regions is very small, and the design of 
Europe is such that it effectively lacks a stabilising fiscal mechanism. As a result, stabilisation in Europe has to be achieved by factor flows and, failing that, by income adjustment. Capital inflows could finance the trade deficit, but could only be expected to do so if alternative investment opportunities arose.

The relative ease with which factors can move within the UK would provide good protection in the case of negative shocks affecting Scotland but not RUK. This scenario is thus, in certain respects, more positive, in terms of the capacity to adjust to negative shocks, than if RUK were outside EMU. But labour force movements in particular are not necessarily ideal as a means of adjustment, as outflows of the more mobile (and thus likely most skilled) labour contribute to a dynamic of decline. Further, there would no longer be any question of fiscal transfers between RUK and Scotland, a factor which other entrants to EMU have not had to consider.

This point raises issues similar to those raised by industrial concentration within Europe, ie issues of the dynamics of growth as opposed to marginal adjustment to imbalances. The economic logic of the single European market is to increase competitiveness, even if that means concentration of economic activity in the golden triangle of south-central Europe. Similarly, the logic of EMU is that the exchange rate tool is substituted for by factor movements and/or wage and price flexibility. This implies the possibility of significant population movements to high productivity areas. The Scotland-in-Europe scenario therefore involves a trade-off between increased Scottish self-determination in some respects and the pursuit of welfare at the European level in others. It is a real policy issue whether the gains from joining EMU might be offset by out-migration of industry and population to other parts of Europe. The dynamic and scale of industry and population movement will change with Enlargement. While the direct effect on Scotland is unlikely to be significant, the indirect effects could be significant in terms of heightening awareness within Europe of issues surrounding small, peripheral economies in a large economic market. It is conceivable that a more systematic European policy for the (peripheral) regions might result.

In the long-term, if specialisation in Europe does make smaller member states unduly vulnerable to negative shocks which cannot be addressed by factor flows, then the Maastricht system will tend to be unworkable because it will itself promote economic divergence. In these circumstances, Delors' earlier proposal for a system of fiscal transfers may then well be revived in order to maintain economic convergence and, more generally, widespread political support. Whether the proposal itself could attract enough support is another matter, really to do with the strength of political commitment to EMU among the more prosperous members.

\section{MECHANISMS FOR MAXIMISING BENEFIT FROM SCENARIO}

If the UK had joined EMU before Scottish independence, there would be little room for manoeuvre for Scotland prior to EMU entry. However, if the UK had not yet joined, there would be scope for Scotland to consider establishing a separate currency prior to entry, with a rate against the pound sterling which better reflected Scotland's relative competitiveness. A sustainable fixed rate against sterling would minimise exchange instability and would ease Scotland's entry. The separate currency during the transition period would also allow for a separate Scottish institutional structure to support Scotland's presence in EMU. Scotland could also take advantage of the more 
favourable exchange rate and the capacity to introduce measures to encourage growth of its key sectors, to take advantage of the scope offered by the European market.

Irrespective of entry route, the high degree of integration between the Scottish and RUK economies (and in particular their factor markets) could provide a cushion for Scotland in the face of particular sectoral shocks. Such shocks could well be highly significant for a small country in Europe, within which concentration and specialisation are being encouraged. Nevertheless, on the downside, factor mobility can sometimes be disequilibrating, with factor outflows from lower-return economies further weakening economic conditions.

The institutional structure of EMU would give Scotland a say in the design of European monetary policy. Some traditional central banking functions might be undertaken by bodies other than the Scottish central bank: the Scottish Treasury would act as government banker and a separate supervisory agency might undertake bank supervision. There would be more latitude here for national policy. Both would involve building up a strong mutually-beneficial relationship with the financial sector, particularly the banks. This in turn would lead to a mutually-beneficial forum for implementing the financial side of industrial policy.

More generally, the Maastricht restrictions are specified at the aggregate level and leave open possibilities for demand-side as well as supply-side measures within those aggregates. Although taxation and regulation are being harmonised across Europe, this does not mean uniformity, so that there would still be some scope for policy addressed to particular Scottish problems and possibilities.

\section{CONCLUSION}

We have considered here the scenario of both an independent Scotland and the rest of the UK being part of EMU. As for the UK as a whole, the issues for Scotland would arise from the particular opportunities created by membership of the euro-zone on the one hand, and the limitations placed on policy autonomy on the other. Joining EMU might seem to imply giving away the scope for policy autonomy which Scotland would achieve with independence. But as a separate member, Scotland would have its own voice in influencing European policy-making. Further, the policy harmonisation process in Europe does not mean uniformity - there would still be scope for some differentiation in policy-making and policy implementation, such as is feasible within a small, relatively cohesive economy like Scotland.

For Scotland, a crucial issue would be the exchange rate at which she entered EMU. Ideally the process of joining would allow a depreciation relative to the rest of the UK. If independence were to arise after the UK had joined EMU, it would be most unlikely that there could be any question of a different exchange rate for Scotland's entry, even if Scotland had to start from scratch in demonstrating that the convergence criteria had been met. But if Scotland were to seek to join EMU before the rest of the UK, there could be strategic advantages in establishing a new interim currency in the transition period, allowing for Scotland then to enter EMU at an exchange rate suited to Scottish economic conditions. 